\title{
Health care provision for illegal immigrants: should public health be concerned?
}

\author{
Alberto M Torres, Belén Sanz
}

European countries are becoming multicultural societies, and national health systems have progressively adapted following their political and historical peculiarities. ${ }^{1}$ Overall, sick, immigrants with regularised administrative status are able to use health services in equal terms than people from the host country. Legal immigrants have a poorer health status and worse living conditions than the host population, and consequently, may even have a higher utilisation of health services, ${ }^{2}$ although that is not always the case. ${ }^{3}$ Ilegal immigrants are, in principle, not entitled to receive medical care from public services, except in cases of emergencies, ${ }^{4}$ but it is unclear where and how they receive medical care in cases of need. In some countries "alternative health care providers" such as non-governmental organisations (NGOs) offer medical care, often supported with public funds. But again, we do not know whether those alternative health care providers are used when they exist, and to what extent they are preferred to other providers. The objective of this study was to test whether illegal immigrants are effectively able to obtain medical treatment when ill.

\section{Methods}

Immigrants from developing countries who resided in one of the Health Areas of the Autonomous Community of Madrid (ACM) (Health Area 6), were older than 15 years of age, and had lived in Spain for more than three months were eligible to enter the study. Our research Area was selected because it had the largest share of immigrants in the ACM. The ACM host about one quarter of the immigrants of Spain, and about one fifth of them lived in our study Area. The southern part of the City of Madrid is part of the study Area and was also included as a potential site for recruitment. Stratified cluster sampling with replacement was used to select 300 immigrants. Twelve per cent of the persons who were approached refused to participate in the study and were replaced by other immigrants, therefore reaching the intended number of 300 . In the first stage, 30 clusters were systematically assigned to towns with a probability proportional to the registered migrant population and 10 migrants were selected and interviewed in each cluster in the second stage. In the second stage, 10 migrants were systematically selected in each cluster. To select immigrants, interviewers had to direct themselves to a predefined area of the municipality, usually the centre of the town, and from there select randomly a direction that would then be followed. Eligible subjects were approached in the streets, or at the door of their homes or at the entrance of common meeting places. Health services and their immediate sorroundings were specifically excluded as potential places for recruitment. Immigrants were systematically approached for interviews irrespective of their nationality or sex. Interviews were conducted starting early in the morning and until late at night. Field work lasted for almost three months. Most often two or even three visits were required to each cluster to complete all the interviews. Survey questionnaire included sociodemographic information, health status and utilisation of health services. Persons who reported having ever been ill in Spain were asked whether they sought medical care for their last episode of illness. Severity of the episode was assessed by a blinded external examiner on the basis of reporting. Administrative legal status was ascertained by one open question: "what is your current administrative status in Spain?" Illegal status was defined as a person who did not have a valid residency permit. As most immigrants to Madrid come from Morocco our questionnaire was translated into Arabic using direct and inverse translation, and completed between February and May of 1997. Data were entered in Epiinfo 6.1, maximum likelihood estimates for odds ratios (ORs) (and 95\% confidence intervals) to explore the likeliness of seeking care the last time the person was ill were estimated using the Csample Module. Multiple logistic regresion analyses were used in the final model to adjust for possible confounders using SPSS.

\section{Results}

Of the 300 persons interviewed, 231 who reported having ever been ill in Spain were included in the analyses. Sixty six were illegal immigrants. Seeking care for the last episode of illness was significantly more frequent if immigrants had legal status (OR: 3.4; 95\% CI 1.9, 6.1) (table 1). Other variables were also associated to the utilisation of health services, namely, sex, national origin, education, knowledge of Spanish, self perception of health status, number of years living in Spain, and severity of the last episode of illness. Age, prior difficulties with the health services, the perception that the migrant has of the quality of health services or of their professionals, and level of income were not associated with seeking medical care in the last episode of illness. Severity of illness, self perceived health status, sex, level of education, number of years living in Spain and origin, could be confounders of the association between legal status and utilisation of health services. Therefore we conducted a multiple logistic regression analysis to adjust for those variables. We found that legal status was still 
Table 1 Utilisation of health services by immigrants who reported having been ill in Spain the last time they felt ill

\begin{tabular}{|c|c|c|c|}
\hline & \multicolumn{2}{|l|}{ The last time ill } & \multirow[b]{2}{*}{ OR $(95 \% C I)$} \\
\hline & $\begin{array}{l}\text { Sought medical } \\
\text { care Number (\%) }\end{array}$ & $\begin{array}{l}\text { Did not seek } \\
\text { medical care } \\
\text { Number \% }\end{array}$ & \\
\hline \multicolumn{4}{|l|}{ Sex } \\
\hline Male^ & $95(75)$ & $32(25)$ & \multirow[t]{2}{*}{$1.9(1.3,2.7)$} \\
\hline Female & $64(61)$ & $40(39)$ & \\
\hline \multicolumn{4}{|l|}{ Origin } \\
\hline Morroco $\star$ & $111(81)$ & $26(19)$ & \multirow[t]{2}{*}{$4.1(2.0,6.8)$} \\
\hline Otherst & $48(51)$ & $46(49)$ & \\
\hline \multicolumn{4}{|l|}{ Administrative status } \\
\hline Legal $^{\star}$ & $123(78)$ & $36(22)$ & \multirow[t]{2}{*}{$3.4(1.9,6.1)$} \\
\hline Illegal & $36(50)$ & $36(50)$ & \\
\hline \multicolumn{4}{|l|}{ Education } \\
\hline No education $\star$ & $27(93)$ & $2(1)$ & 1 \\
\hline Basic education & $100(71)$ & $41(29)$ & $0.2(0.4,0.8)$ \\
\hline Higher education & $29(52)$ & $27(48)$ & $0.1(0.1,0.4)$ \\
\hline \multicolumn{4}{|l|}{ Literacy in Spanish } \\
\hline Yes $^{\star}$ & $90(63)$ & $53(37)$ & \multirow[t]{2}{*}{$0.5(0.3,0.8)$} \\
\hline No & $67(78)$ & $19(22)$ & \\
\hline \multicolumn{4}{|l|}{ Lives with family } \\
\hline Yes ${ }^{\star}$ & $122(67)$ & $60(33)$ & \multirow[t]{2}{*}{$0.7(0.2,2.4)$} \\
\hline No & $35(75)$ & $12(26)$ & \\
\hline \multicolumn{4}{|c|}{ Self perceived health status } \\
\hline Good $^{\star}$ & $55(61)$ & $35(39)$ & \multirow[t]{2}{*}{$0.6(0.4,0.9)$} \\
\hline Poor & $104(73)$ & $37(27)$ & \\
\hline \multicolumn{4}{|c|}{ Past problems with health service } \\
\hline Yes $^{\star}$ & $46(71)$ & $20(29)$ & \multirow[t]{2}{*}{$1.1(0.6,1.8)$} \\
\hline No & $111(68)$ & $52(32)$ & \\
\hline \multicolumn{4}{|c|}{ Ever denied medical assistance } \\
\hline Yes $^{\star}$ & $30(65)$ & $16(35)$ & \multirow[t]{2}{*}{$0.8(0.4,1.6)$} \\
\hline No & $127(70)$ & $56(30)$ & \\
\hline \multicolumn{4}{|l|}{ Severity of illness } \\
\hline Small* & $86(61)$ & $54(39)$ & \multirow[t]{2}{*}{$0.4(0.2,0.8)$} \\
\hline Moderate/severe & $71(83)$ & $16(17)$ & \\
\hline
\end{tabular}

* The first category of each variable has always been used as the reference category in the calculation of the ORs. †"Others" category includes: Dominican Republic (38), Peru (26), Ecuador (22), Colombia (12), and other countries represented by less than three persons (Philippines, Rumania, Mexico, Brasil, Chile, China, Algeria, Equatorial Guinea, Cape Verde Island, Nicaragua, Guatemala, Cuba, Bolivia, Mauritania and Poland).

significantly associated, although with a smaller odds ratio (OR: $2.6 ; 95 \%$ CI: $1.2,5.8$ ) with utilisation of health services.

\section{Discussion}

This study provided evidence of a strong barrrier to health care utilisation for sick illegal immigrants. The cross sectional design in our study may have induced some misclassification as legal status was ascertained at the time of the interview and not at the time of illness. However, in that situation differential misclassification towards the null is even more probable because administrative processes of "regularisation" have taken place often in Spain since 1991. Therefore, it is possible that the association we found underestimates the true magnitude of the barrier that illegal immigrants have to use health services. The characteristics of the population under study also impose some limitations, mainly selection bias. We did not have a defined sampling frame therefore equal probability selection for all immigrants living in the area could not be achieved. Through our sampling scheme those people who spent more time on the street looking for a job or just walking were more likely to be chosen than those that might drive a car to work. However, to explain those differences as bias it should be necessary that diferential missclasification had occurred and that we had selected illegal immigrants who do not used health services when ill with a higher probability than illegal immigrants who used them, or conversely, that legal immigrants who did not used health services when ill had a lower probability of selection than those who used them, which is unlikely.

Our findings suggest, after adjusting for severity of illness, number of years living in the country, and other possible confounders, that sick illegal immingrants use health services significantly less often in Spain that legal ones. Studies in other settings tackling some of the limitations in our study would be desirable. As illegal immigrants live in especially precarious circumstances the low utilisation of curative services found in this study raises important concerns whether the strategy of health care provision through alternative providers is effectively able to meet the health needs of illegal immigrants. The large percentage of illegal immigrants found in our study adds to the concern. As the needs of illegal immigrants are rarely heard specific policies have remained unquestionned. Although the health problems of immigrants have received attention in Europe, ${ }^{5}$ public health has often played a dubious part towards illegal immigrants mostly guided by a concern to detect and control infections, but insufficient support to guarantee access to health care services. The health of illegal immigrants should be reconsidered, and, as a basic human right, be of primary concern to public health. ${ }^{67}$ Funding: this study was funded by the Fondo de Investigaciones
Sanitarias (Spain) and a Research Fellowship of the Instituto de Sanitarias (Spain)
Salud Carlos III.

Conflicts of interest: none.

1 Bollini P. Health policies for inmigrant populations in the 1990 s. A comparative study in seven receiving countries. International Migration. Quaterly Review 1992;XXX:10319

2 Reijneveld SA. Reported health, lifestyles and use of health care of first generation immigrants in The Netherlands: do socioeconomic factors explain their adverse position? $f$ Epidemiol Community Health 1998;52:398-404.

3 Remennick LI. Preventive behavior among recent immigrants: Russian-speaking women and cancer screening in Israel. Soc Sci Med 1999;48:1669-84.

4 Bollini P, Siem H. No real progress towards equity: health of imigrants and ethnic minorities on the Eve of the year 2000. Soc Sci Med 1995;41:819-28.

5 Carballo M, Divino J, Zeric D. Migration and health in the Carballo M, Divino J, Zeric D. Migration and health in
European Union. Trop Med Int Health 1999;3:936-44.

6 Mann JM. Health and human rights. BMF 1996;312:924-5.

7 Krieger N, Birn AE. A vision of social justice as the foundation of public health: commemorating 150 years of the spirit of 1848. Am F Public Health 1998;88:1603-6. 